\title{
Review: intrinsic and environmental risk factor modification reduces falls in elderly people
}

\author{
Gillespie LD, Gillespie WJ, Robertson MC, et al. Interventions for preventing falls in elderly people. Cochrane Database Syst \\ Rev 2001;(3):CD000340 (latest version 19 May 2001).
}

Source of funding: Department of Health, Scottish Office, UK

For correspondence Mrs L D Gillespie, University of Otago, Dunedin, New Zealand. lesley.gillespie@ stonebow.otago.ac.nz.

\section{QUESTION: In community dwelling and institutionalised elderly people, how effective are programmes designed to reduce the incidence of falls?}

\section{Data sources}

Studies were identified by searching 8 databases. Bibliographies of relevant studies were reviewed, and researchers in the field were contacted for unpublished trials.
Interventions for preventing falls in unselected community dwelling elderly people $(U)$ or in community dwelling elderly people with a history of falls or fall risk factors $(R) *$

\begin{tabular}{|c|c|c|c|c|c|}
\hline $\begin{array}{l}\text { Outcomes at } \\
\geqslant 44 \text { weeks }\end{array}$ & Group & Comparison & $\begin{array}{l}\text { Weighted } \\
\text { event rates }\end{array}$ & $\operatorname{RRR}(95 \% \mathrm{Cl})$ & NNT (Cl) \\
\hline \multirow{3}{*}{ NPF } & $\mathrm{R}$ & MSB $v$ control & $36 \%$ v $45 \%$ & $20 \%$ (2 to 36$)$ & 12 (6 to 100$)$ \\
\hline & $U$ & AFMI $v$ control & $24 \%$ v $33 \%$ & $27 \%(14$ to 37$)$ & 12 (8 to 23 ) \\
\hline & $\mathrm{R}$ & AFMI $v$ control & $45 \%$ v $57 \%$ & $21 \%$ (6 to 33$)$ & $9(6$ to 28$)$ \\
\hline NSIF & $\mathrm{R}$ & MSB $v$ control & $22 \%$ v $33 \%$ & $33 \%(11$ to 49$)$ & 10 (6 to 32$)$ \\
\hline
\end{tabular}

${ }^{*} \mathrm{AFMI}=$ assessment followed by multifactorial intervention; $\mathrm{MSB}=$ muscle strengthening and balance retaining; $\mathrm{NPF}=$ number of people falling; NSIF = number sustaining a fall with injury. Other abbreviations defined in glossary; RRR, NNT, and Cl calculated from data in article using a fixed effects model.

\section{COMMENTARY}

The review by Gillespie $e t$ al clearly shows that several interventions are effective in reducing falls in older people generally and in those with an established risk for falls. Most research has been done in the community setting where evidence is strongest. The challenge of preventing falls in hospital and residential elderly care settings differs from that in community settings and may limit the generalisability of these results. Comprehensive assessment and targeted management programmes seem to be the best approach across settings. However, consensus does not exist about the type of risk factor assessment that should be done. ${ }^{1}$ Multidisciplinary falls clinics, which use a comprehensive assessment and management programme for those at high risk for falling, ${ }^{2}$ have not been evaluated in RCTs.

Exercise is the most extensively investigated single intervention. Common to most of the exercise programmes that have shown reduced falls is a balance component ${ }^{3}$ (eg, tai chi $^{4}$ and individualised home exercise programmes). ${ }^{5}$ Strength training has also formed part of successful fall prevention programmes.

Further research should focus on hospital and residential elderly care settings and on people at high risk for falls (eg, patients with dementia, stroke, and Parkinson's disease). Additionally, studies investigating strategies for increased adherence to effective interventions are also required.

Keith Hill, PhD National Ageing Research Institute Parkville, Victoria, Australia

1 Perell KL, Nelson A, Goldman RL, et al. Fall risk assessment measures: an analytic review. J Gerontol A Biol Sci Med Sci 2001;56:M761-6.

2 Hill K, Smith R, Schwarz J. Falls clinics in Australia: a survey of current practice, and recommendations for future development. Aust Health Rev 2001;24:163-74.

3 Province MA, Hadley EC, Hornbrook MC, et al. The effects of exercise on falls in elderly patients: a preplanned meta-analysis of the FICSIT trials. Frailty and Injuries: Cooperative Studies of Intervention Techniques. JAMA 1995;273:1341-7.

4 Wolf SL, Barnhart HX, Kutner NG, et al. Reducing frailty and falls in older persons: an investigation of tai chi and computerised balance training. Atlanta FICSIT Group. Frailty and Injuries: Cooperative Studies of Intervention Techniques. J Am Geriatr Soc 1996;44:489-97.

5 Campbell AJ, Robertson MC, Gardner MM, et al. Randomised controlled trial of a general practice programme of home based exercise to prevent falls in elderly women. $B M J$ 1997;315:1065-9.

\section{Study selection}

Studies in any language were selected if they were randomised controlled trials (RCTs) designed to minimise the effect of or exposure to any risk factor for falling; if they compared an intervention or group of interventions with usual care or alternative care; and if participants were elderly people living in the community or in institutional care.

\section{Data extraction}

Data were extracted on setting, patient inclusion and exclusion criteria, sample size, key components of the intervention, study quality, and outcomes. Outcomes were the number of people who fell, the number of falls, and the severity of falls.

\section{Main results}

40 studies met the selection criteria. 14 RCTs evaluated exercise or physiotherapy interventions: participants in an individually tailored programme of progressive muscle strengthening, balance-retaining exercises, and a walking plan (3 RCTs) had lower rates of falls and injurious falls than did control group participants at 1 year (table). Participants exposed to a 15 week tai chi untargeted group intervention (1 RCT) had a lower rate of falling than did control group participants (risk ratio [RR] $0.51,95 \%$ CI 0.36 to 0.73 ). 1 RCT evaluated a home safety intervention by an occupational therapist: among patients with a history of $\geqslant 1$ fall in the previous year, the rate of falls was lower in the intervention group than in the control group (RR 0.64, CI 0.49 to 0.84 ). 1 RCT evaluated a placebo controlled medication withdrawal programme: the overall risk for falls was lower for the psychotropic medication withdrawal group (relative hazard 0.34 , CI 0.16 to 0.74 ). Multidisciplinary, multifactorial, health, or environmental risk factor screening or intervention programmes, both for unselected community dwelling older people and for older people selected because of known risk factors, were evaluated in 7 and 2 RCTs, respectively. For both unselected (3 RCTs) and selected people (2 RCTs), the intervention groups had lower rates of falls than did control groups (table).

\section{Conclusions}

In community dwelling elderly people, intervention programmes that target both intrinsic and environmental risk factors may reduce the incidence of falls. However, evidence of effectiveness in institutional settings is lacking. 